\title{
Development of a New Downscale Setup for Wheel-Rail Contact Experiments under Impact Loading Conditions
}

\author{
Meysam Naeimi $^{1} \cdot$ Zili Li $^{1}$ (D) Roumen H. Petrov $^{2,3} \cdot$ Jilt Sietsmaa $^{2,3} \cdot$ Rolf Dollevoet $^{1}$
}

Received: 25 February 2017 / Accepted: 7 October 2017 / Published online: 30 October 2017

(C) The Author(s) 2017. This article is an open access publication

\begin{abstract}
A new downscale test rig is developed for investigating the contact between the wheel and rail under impact-like loading conditions. This paper presents the development process of the setup, including review and synthesis of the potential experimental techniques, followed by scalability, mechanical and operational analysis of the new setup. The new test rig intends to remedy the lack of dynamic similarity between the actual railway and the existing laboratory testing capability, by taking into account the factors that contribute to high-frequency dynamics of the wheel-track system. The paper first reviews the functionalities of the existing test techniques in the literature. Based on this survey, the category of the scaled wheel on the rail track ring is chosen. Afterwards, three potential alternatives are identified under the chosen category and the optimum mechanism is achieved through finite element modelling and analysis of the structures. A downscale test rig, consisting of multiple wheel components running over a horizontal rail track ring, effectively fulfilled the requirements needed for analogical testing of the wheel-rail contact behaviour. The new test rig is a unique experimental setup due to the involvement of high-frequency dynamic vibrations in the wheel-track system and analogy of the incorporated elements and loading to those of the real-life system. This
\end{abstract}

Zili Li

Z.Li@tudelft.nl

1 Section of Railway Engineering, Faculty of Civil Engineering and Geoscience, Delft University of Technology, Delft, the Netherlands

2 Department of Materials Science and Engineering, Delft University of Technology, Delft, the Netherlands

3 Department of Materials Science and Engineering, Ghent University, Ghent, Belgium paper further presents the results of some real experiments carried out using the newly-built setup to support substantial ideas behind its development.

Keywords Test rig $\cdot$ Scale $\cdot$ Wheel-rail contact $\cdot$ Dynamic $\cdot$ Experiment

\section{Introduction}

Railways and especially high-speed trains are popular transportation modes due to being sustainable, economical and environmentally friendly. Rolling contact fatigue (RCF) is an important degradation source of the wheel and rail materials in the railway industry. In the past few decades, researchers have attempted to identify the physical mechanisms involved in RCF of rails and wheels and proposed diverse models to predict their fatigue life; see e.g. [1-3]. Such studies and many other examples have substantially contributed to the prediction of the lifetime of rails and wheels and to optimization of maintenance strategies by avoiding or delaying RCF.

Although detailed models of the wheel-rail contact and damages, as well as vehicle-track interaction have been developed, further field characterization and experimental verifications are needed to better understand the root causes of the RCF. These include the development of repeatable testing methodologies that can manifest the true states of contact stresses of the wheel-rail system and reveal the actual causality of microstructure changes under realistic loading conditions. To such end, a new test rig is developed in the current research. The aim is to provide a brand-new test facility, which enables the researchers to generate RCF of rails and wheels under scaled and controlled laboratory conditions. With this rig we intend to provide the following four functional goals: (1) to examine the validity of the various hypotheses on 
damage occurrence; (2) to gain new insight into damage mechanisms from the extended viewpoint of mechanical loading and material properties at macro level and at the microstructure scale; (3) to test material performance for damage resistance and (4) to support the development of new materials and damage prediction models. The present study addresses how the new setup can fulfil the above-mentioned four functionality requirements. The damages include plastic deformation, wear and RCF. In particular, the focus of the new test rig will be on impact-induced RCF defects such as squats, as they involve all these damages [4]. The test rig can also be applied to other similar defects (in terms of their dynamic loading) like poor insulation joints, wheel flats and wheel burns, poor welds and corrugation $[4,5]$. It is expected that tests for other types of RCF, e.g. head-checking, can also be conducted, if the loading is reduced to a (quasi-) static state.

High-frequency dynamics of wheel-rail and train-track interaction is not yet well understood. It mostly has to do with wheelrail dynamic contact and is very much determined by the track flexibility and nonlinearities, effects of which are mostly not yet well established. One specific example is corrugation, which not only causes acoustic noises, but RCF (squats) and damages fastening. This might lead to chain effects as many fastenings might break one after another in a short time between inspection intervals and thus might cause a catastrophic derailment, as well as fast degradation of ballast/slab and other components. The new test setup can test almost any type of track structures e.g. ballast track, slab track, embedded track with including their real material nonlinearities.

This paper first briefly reviews the existing rigs that can be used for general wheel-rail contact studies. The paper further assesses the suitability of the existing experimental setups for research on impact-induced RCF defects. This evaluation leads to three preferred experimental techniques, which are then further assessed in more detail. Consequently, an optimum mechanism is achieved through technical evaluations and synthesis of the structures, characteristics and performance. Afterwards, specifications of the new test setup are described and some results of dynamic measurements are presented. Experimental observations in the test setup are finally compared with those of the real-life railway to reveal dynamic similarities and to see the potentials for screening RCF in the new rig.

\section{Review of the Existing Test Rigs for Wheel-Rail Contact Studies}

Various experimental techniques were proposed in the literature for wheel-rail contact studies. The testing procedures for fatigue testing of metals are fairly established in terms of methodologies, instruments and the applications. Some experimental methods were introduced for RCF experiments in bearing steels. A collection of methodologies devoted substantially to rolling bearings were presented in [6]. In contrast to rolling bearings, the experimental methods for assessing RCF in wheel-rail materials, involved much uncertainty about the functionality of different techniques and their effectiveness. Table 1 summarises a list of various test rigs for wheel-rail contact investigations either within full-scale or reduced-scale configurations in the literature. The scale parameter in this table indicates the overall scale of the wheel (its diameter) relative to the standard railway wheel.

Looking at the scale parameter in Table 1, the existing test rigs can be classified into two main categories: Full-scale and reduced-scale. General classification of the existing test rigs is shown in Fig. 1. According to this figure, six general categories are defined: 1) Full-size vehicle/ bogie, 2) Full-size wheel-onroller, 3) Full-size wheel-on-straight, 4) Twin-discs, 5) Scaled wheel on rail track ring and 6) Scaled wheel on the straight track.

A comparative evaluation is carried out in the following, to select an optimum category for the new test rig in this research. Although any of these six categories is able to simulate some aspects of the rolling contact problem, some specific demands are defined for the new test rig in this paper to evaluate the six categories. Compliance of the above-mentioned categories is evaluated toward these criteria.

\section{High-Frequency Vibrations}

It has commonly been agreed by [38-42] that the primary suspension of a railway vehicle plays a more significant role in the wheel-rail interaction problem than the secondary suspension. Hence, the secondary suspension of the vehicle can be handled with less detail in order to develop a new rig for the wheel-rail contact problem. This simplification is acceptable because the vibration of the sprung mass has a negligible effect on dynamic properties of the wheel-rail contact problem. This is because the wavelength of vibrations of the sprung mass, in the order of meters, is much longer than the size of contact patch between the wheel and rail $[42,43]$. This means that for the purpose of high-frequency dynamic investigation in the wheel-rail contact, it is not essential to include the vehicle or bogies with their complex configurations into the testing procedure. Thus, the mass of the vehicle system can be lumped above the wheel component, where it is supported by a group of springs and dampers of the vehicle's primary suspension; see Fig. 2. In order to manifest highfrequency dynamics in the test rig, it is of major importance to include the required flexibilities and nonlinearities in the wheel-rail dynamic contact problem. This can be achieved by using identical material properties for the wheel-track system. The majority of the existing test rigs are used to study the wear in wheel-rail materials or to examine the head-checks which happen due to quasi-static loading [44]. Although the new test rig is developed to study all the major types of RCF defects, the main focus is on squats, which are associated with highfrequency dynamics in the wheel-track system. 
Table 1 A list of available test rigs for wheel-rail contact studies

\begin{tabular}{|c|c|c|c|c|}
\hline No. & Name of the testing setup & Scale & Owner & Location \\
\hline 1 & Vehicle/Bogie Roller Rig [7] & $1: 1$ & Deutsche Bahn AG (DB AG) & Munich-Freimann, Germany \\
\hline 2 & Full-scale Roller Rig [8] & $1: 1$ & Southwest Jiaotong University (SWJTU) & Chengdu, China \\
\hline 3 & DTR Dynamic Train Bogie Test Rig [9] & $1: 1$ & Danobat Group, Railway Unit & Elgoibar, Spain \\
\hline 4 & Full-scale Roller Stand [10] & $1: 1$ & National Traffic Safety \& Envir. Lab. (NTSEL) & Tokyo, Japan \\
\hline 5 & Wheel-Rail Test Rig [11] & $1: 1$ & University of Sheffield (formerly RSSB) & Sheffield, UK \\
\hline 6 & Full-scale Rail Wheel Test Rig [12] & $1: 1$ & Voestalpine Schienen (VAS) & Leoben, Austria \\
\hline 7 & Wheelset Roller Rig [13] & $1: 1$ & Deutsche Bahn AG (DB AG) & Munich, Germany \\
\hline 8 & Wheel Test Rig [7] & $1: 1$ & Fraunhofer Institut Betriebsfestigkeit (FIB) & Darmstadt, Germany \\
\hline 9 & BU300 Roller Rig $[14,15]$ & $1: 1$ & Lucchini C.R.S & Lovere, Italy \\
\hline 10 & Naples Vehicle Roller Rig [16] & $1: 1$ & Ansaldo Transport Research Centre & Naples, Italy \\
\hline 11 & Osmannoro Full-scale Roller Rig [17] & $1: 1$ & Osmannoro Research Centre & Florence, Italy \\
\hline 1 & Reduced-scale Rolling Rig $[18,19]$ & $1: 3$ & TNO-TPD & Delft, Netherlands \\
\hline 2 & Wheel/Rail Tribological Rolling Rig [20] & $1: 4$ & Southwest Jiaotong University & Chengdu, China \\
\hline 3 & UNSW Wheel-Rail Rolling Rig [7] & $1: 5$ & University of New South Wales & Sydney, Australia \\
\hline 4 & Scale Roller Rig [21] & $1: 5$ & University of Huddersfield (formerly MMU) & Huddersfield, UK \\
\hline 5 & Twin-Disk Rig [22] & $1: 3$ & University of Huddersfield (formerly MMU) & Huddersfield, UK \\
\hline 6 & Two-Disc Test Rig [23] & $\sim 1: 5$ & University of Queensland & Sydney, Australia \\
\hline 7 & Scaled-Bogie Test Bench [24] & $1: 5$ & Université Catholique de Louvain & Louvain, Belgium \\
\hline 8 & SUROS Twin-Disk Test Machine [25] & $\sim 1: 20$ & Sheffield University Rolling Sliding & Sheffield, UK \\
\hline 9 & ISVR Wheel-Rail Test Rig [26, 27] & $1: 5$ & Institute of Sound \& Vibration Research & Southampton, UK \\
\hline 10 & BCRRE Spinning Rail Test Rig [28] & $\sim 1: 7$ & University of Birmingham & Birmingham, UK \\
\hline 11 & INRETS Bogie Test Rig [29, 30] & $1: 4$ & French Transport Research Institute (INRETS) & Grenoble, France \\
\hline 12 & Scaled Wheelset Roller Stand [31] & $1: 5$ & National Traffic Safety \& Environ. Lab. (NTSEL) & Tokyo, Japan \\
\hline 13 & Oerlikon Test Machine [32] & $\sim 1: 10$ & Delft University of Technology & Delft, Netherlands \\
\hline 14 & Scaled wheel on rail track-wheel Test Rig [33] & $1: 3$ & Cranfield University & Cranfield, UK \\
\hline 15 & Twin-Disc Rolling-Sliding Machine [34] & $\sim 1: 2$ & Railway Technical Research Institute & Tokyo, Japan \\
\hline 16 & Twin-Disc Machine [35] & $1: 2-1: 4$ & East Japan Railway Company (JR East) & Saitama, Japan \\
\hline 17 & Scaled Roller Test Rig [36] & $1: 5$ & MDM Lab & Pistoia, Italy \\
\hline 18 & Scaled Bogie on Rollers [37] & $\sim 1: 5$ & Delft University of Technology & Delft, Netherlands \\
\hline
\end{tabular}

\section{Details Down to Track Components}

In a typical ballasted railway track, the support system is composed of fastenings, sleepers and ballast layer. Field observations have shown that the wheel-rail dynamic forces can be directly transferred from the contact interface to the track components and exacerbate the deterioration rate of the track components $[45,46]$. Conversely, the presence of defects and imperfections in track components can also contribute to highfrequency vibrations of the wheel-track system [43, 47]. The results of vehicle-track dynamic simulations in [48] show that the presence of singular rail surface defects (squat for instance) can significantly increase high-frequency dynamic forces between the wheel and rail. Furthermore, the stiffness and damping properties of rail fasteners, and in particular the railpads, have been shown to play an important role in dynamic behaviours of the railway system, especially in the highfrequency range [49]. Some surveys such as [50, 51] have examined the relationship between the track geometry and the formation of RCF defects, where track maintenance was also found to be related to RCF initiation. Such studies indicate the importance of incorporating the major track components to deal with impact-loading conditions. The term "impact" is used here to characterise the short period and highly dynamic wheel-rail contact at irregularities in the wheel/rail surface such as indentation, squats, rail joint, wheel flat or other defects. Such term has also been used for the same purpose by other researchers; see e.g. [39, 46]. It is possible to create all of these (irregularities, joints, track defects, etc.) in the wheel-track components of the new test rig. This enables us to study the wheel-track system similar to the real life.

\section{Scaling Concept}

From a general standpoint, reduced-scale testing generally costs less and is more convenient to conduct than the 
Fig. 1 Classification of possible test rig mechanisms for wheel-rail contact studies

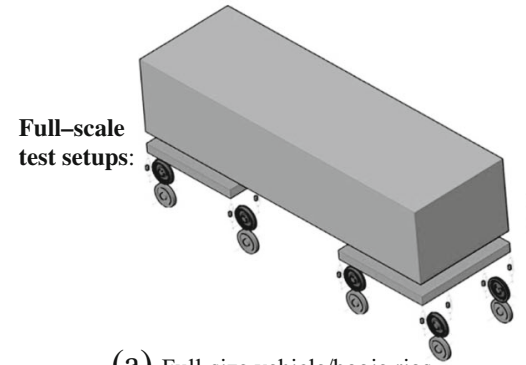

(a) Full-size vehicle/bogie rigs

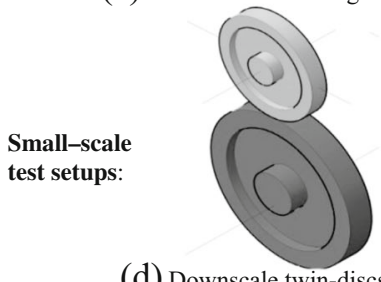

(d) Downscale twin-discs

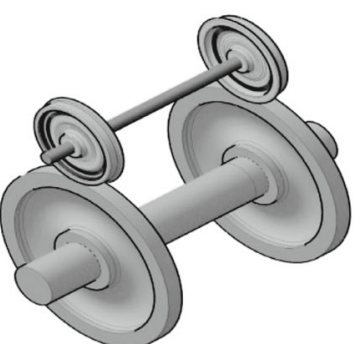

(b) Full-size wheel on roller

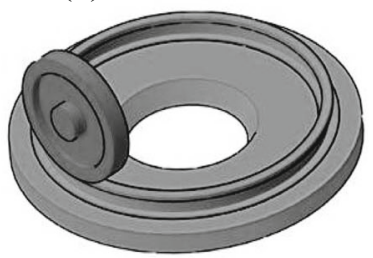

(e) Scaled wheel on rail track ring

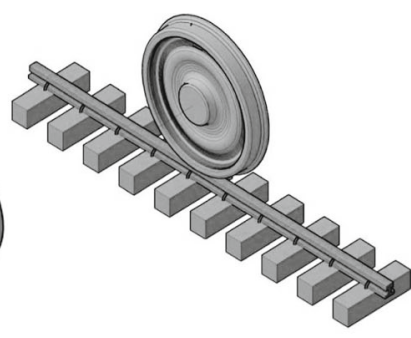

(c) Full-size wheel on straight track

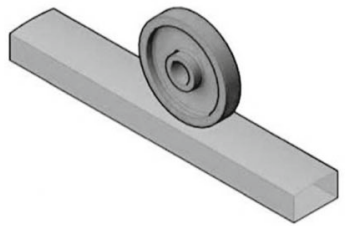

(f) Scaled wheel on straight rail full-scale testing. Furthermore, for the present research, monitoring and controlling the effective factors on the RCF problem necessitate a large number of tests to be carried out. In a reduced-scale setup, of course, it would be easier and less costly to implement a wider range of tests. On the other hand, a full-scale test rig may incorporate the whole body of the railway vehicle (Fig. 2), which is more realistic from the vehicle dynamics point of view. The major concern about the scaled test rigs is the uncertainty about the equivalency of the system when the scaling is applied. For this reason, researchers often argued the similarity issues of the scaled test rigs. Various similarity strategies of the scaled test rigs were discussed in [30, 52], indicating their benefits and limitations. Another example of the similarity analysis on the parameters of a wheel-track test rig is provided in [53]. A more recent study [54], reports the application of similarity law for a small-scale derailment simulator. By using a suitable scaling strategy, it is plausible to derive the parameters of the new test rig equivalent to the real-life system.

\section{The Ring Track Mechanism}

A fundamental limitation of the test rigs with straight track mechanisms (Fig. 1(c, f)) is the low rolling speed of the wheel. This is because the wheel cannot continuously run over the rail and thus it has to move back and forth in a cyclic manner to simulate the repeated contact. With such a mechanism, a realistic simulation of the vehicle-track system will be difficult to achieve. It also causes un-realistic transient non-steady state, making required test conditions disturbed or needing a long time to achieve. Furthermore, it is more demanding on the loading and running mechanism. Hence, to provide repeated contact condition with an acceptable range of speed and realistic transient state of the system under unidirectional rolling, it is almost unavoidable to use a rail with a circular shape, either with disc or ring. This is the main reason why many of the existing rigs simulate track with the disc, roller or ring.

Continuous rolling contact can also be achieved by the simple twin-disc strategy, where the rail-disc and wheel-disc drive with opposite angular velocities against each other; see
Fig. 2 Dynamic model of the vehicle-track system with simplification in vehicle structure and with detailed modelling of the track to manifest high-frequency vibrations in the test environment

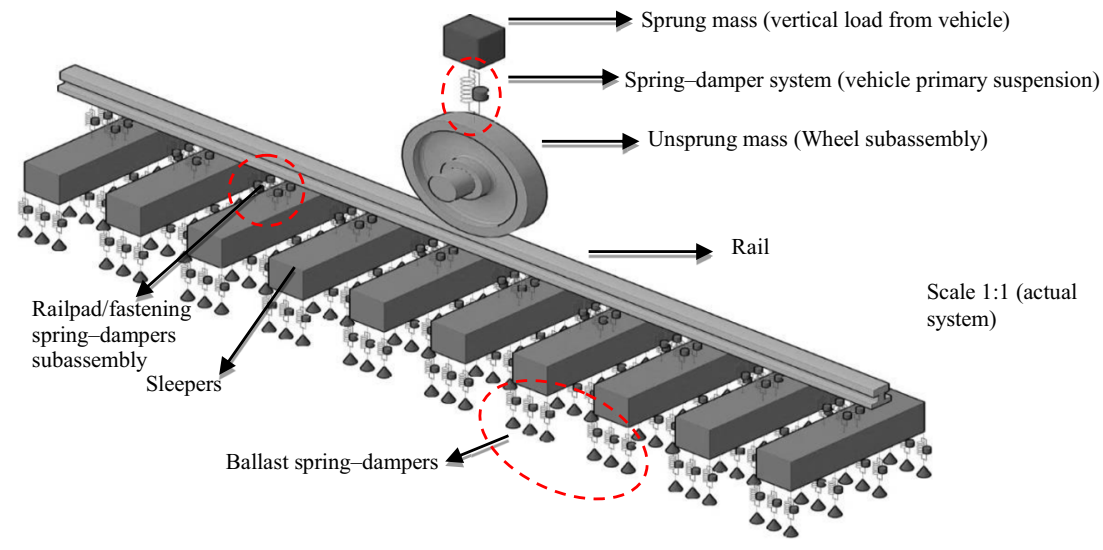


Fig. 1(d). However, the behaviour of the rail track is neglected in such a mechanism as the track is excluded. Lack of similarity in dynamic characteristics of the vehicle-track system and its flexibility features are the major limitations of the twindisc categories. Therefore, the rail disc mechanism cannot fulfil the requirements needed for RCF tests in the current research. By employing a bent track structure (ring track), it is possible to provide the test rig with a continuous rolling contact, while the important dynamic analogies are maintained.

By evaluating the mentioned six categories toward the prescribed requirements, one category provides more advantages for developing a new rig for the wheel-rail contact studies. This category is the scaled wheel on a scaled rail track ring (Fig. 1(e)). The main advantages are: 1) It uses a reduced-scale strategy to benefit from the reduced-scale experiments i.e. convenience, cost effectiveness, operational safety, flexibility etc.; 2) The level of simplification on the vehicle is up to primary suspensions, which is adequate for the purpose of the wheel-rail contact research; 3) All components of the track system are incorporated, contributing to the dynamic properties of the wheel-rail contact problem; 4) A continuous rolling contact can be simulated due to the ring-shaped application. Table 2 summarizes the beneficial assets that can be achieved with the selected category. The table also gives some design features that need to be considered to fulfil the prescribed requirements.

\section{Development of the New Rig under the Selected Category}

Based on the above discussion, the qualified category is a downscale wheel-track mechanism consisting of equivalent components of an actual railway system. The vehicle primary suspension and the track components need to be incorporated, (Fig. 2) to simulate analogical behaviours of the vehicle-track system. In the following, further assessment is undertaken on the selected category. The stable positioning of the wheeltrack system in the selected category can be provided through different mechanisms. Three alternatives within this category are defined as shown in Fig. 3. The track structure in all the alternatives consists of rail, fastenings, sleepers and ballast. The track assembly is stationary in all the three alternatives, while the wheel assembly rolls over the rail.

In the following sections, these three alternatives are comparatively assessed from the structural and mechanical viewpoints to determine the most suitable one. The Finite element method (FEM) is employed to assess the alternatives under the rolling contact condition.

\section{Scalability in the New Test Rig}

Scalability is a fundamental subject when dealing with downscale test setups. The scale factor defines the dimensions and it affects the parameters of the components in the test setup. The choice of material properties is also an important factor in the scaling problem. The starting point for the scalability in this research is to keep similarity of the wheel-track system to the real-life one. To achieve this, a linear geometric scaling, i.e. applying a particular scale factor on all dimensions is used, whereas the material properties are kept the same. References $[29,30,52-55]$ are some examples of studies on scaling strategies in railway-related test setups. The scaling rules in these works were based on reducing all geometrical dimensions by a scale factor $\mathrm{N}$, whereas the scales on other parameters were calculated by relationships between different variables.

As described in [30], a scaling strategy needs to be selected based on the type of analysis work to be carried out on the rig. Some scaling strategies were classified and comparatively evaluated in [30]. These strategies were useful approaches for the studies on dynamics and stability of railway vehicle/ bogie. The wheel-track system in this research is going to be extensively used for contact mechanics studies. The contact problem involves high-frequency dynamics of the wheel-rail interaction and nonlinearities in materials. The scaling strategy of the current research is shown in Table 3, by addressing the required scale factors on different variables.

The value $N$ in Table 3 stands for the overall scale of the test rig, while different scale factors on each parameter are
Table 2 Benefits for the selected category (the scaled wheel on the rail track ring)

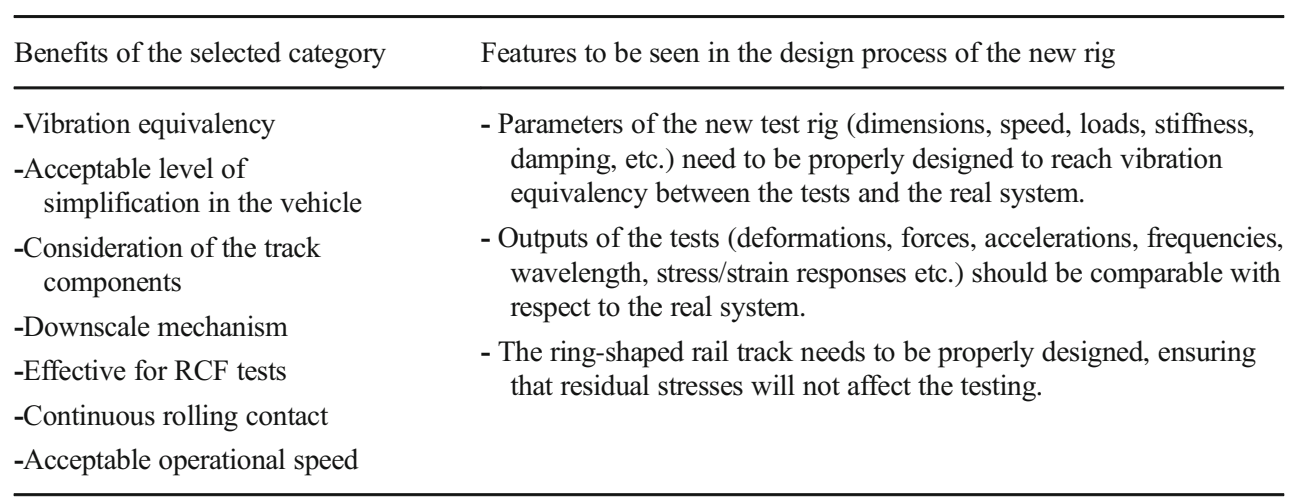


Fig. 3 Schematic view of the three plausible alternatives within the qualified category; $\mathrm{RD}=$ rolling direction, $\mathrm{NT}=$ normal track vector

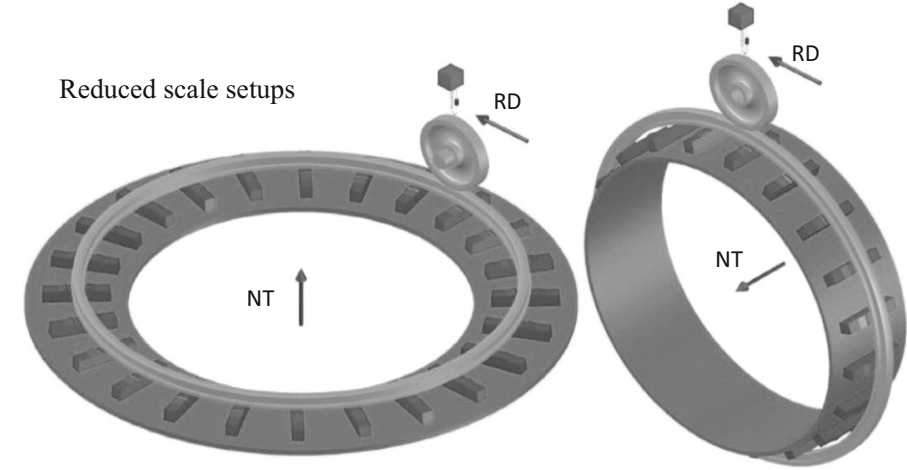

(a) Alt-1. Rotating wheel on a horizontal rail track ring (b) Alt-2. Rotating wheel on outer side of a vertical rail track drum

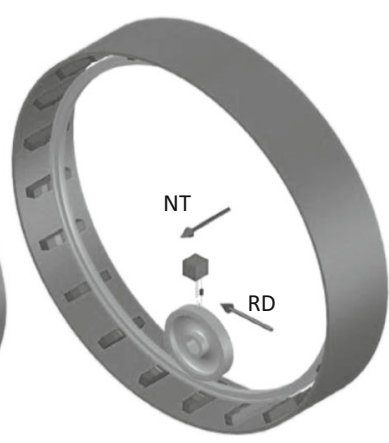

(c) Alt-3. Rotating wheel on inner side of a vertical rail track drum shown with $\phi$ factors. Considering $\phi_{L}=N$ on spatial dimensions, the other scale factors are obtained for the other parameters in Table 3, e.g. for acceleration $\phi_{a}=\phi_{L} / \phi_{t}{ }^{2}=1 / N$. The scale factor on time can be interpreted by the scaled duration of the experiment needed for running on a configuration with the scaled dimensions. It can also be interpreted by the increased number of contact cycles (by a factor of $\mathrm{N}$ ) that a downscale wheel can create when running on the track. A similar time scaling is also used by the INRETS test rig in the literature [30].

The chosen strategy provides the following advantages: 1) the scale factor on any parameter is obtained by keeping the quantities of material specification (e.g. density $\rho$, Young's modulus $E$ and Poisson's ratio $\nu$ ) unchanged. It is important that the nature of fatigue and fracture in the test rig components (more importantly in wheels and rails) be the same as the real life system. This can be achieved when material properties are the same as reality. 2) This scaling strategy keeps the stress and strain in materials the same as reality. This is again important due to the tendency for having the same fatigue and fracture mechanisms in the wheel-track system. 3) The chosen scaling strategy does not consider any scale factor on the friction and traction coefficients. Thus, the tribological behaviours of the wheel-rail system are kept similar to reality. This is of significant importance as some RCF defects (e.g. wheel flat) occur due to tractive/braking efforts. The scaling strategy of this research has also been successfully experimented in $[29,53]$.

In order to simulate and design the test rig in this research the scale factor of 1:5 was tentatively selected for the three alternatives. The dimensions of the wheel and rail were determined, by scaling the actual geometries (wheel profile S1002
Table 3 Scaling strategy of the new test rig, scale factor on different variables

\begin{tabular}{lllll}
\hline Variable/ parameter & Variable notation & Units & Scale factor notation & Scale factor \\
\hline Length & $L$ & $m$ & $\phi_{L}$ & $N$ \\
Cross section & $A$ & $m^{2}$ & $\phi_{A}$ & $N^{2}$ \\
Volume & $V$ & $m^{3}$ & $\phi_{V o l}$ & $N^{3}$ \\
Inertia & $I$ & $m^{4}$ & $\phi_{I}$ & $N^{4}$ \\
Density & $\rho$ & $k g / m^{3}$ & $\phi_{\rho}$ & 1 \\
Mass & $M$ & $\phi_{M}$ & $N^{3}$ \\
Young's modulus & $E$ & $N / m^{2}$ & $\phi_{E}$ & 1 \\
Poisson's ratio & $\nu$ & $N o n e$ & $\phi_{\nu}$ & 1 \\
Force & $F$ & $N$ & $\phi_{F}$ & $N^{2}$ \\
Creep/tangent force & $T$ & $N$ & $\phi_{T}$ & $N^{2}$ \\
Stress & $\sigma$ & $N / m^{2}$ & $\phi_{\sigma}$ & 1 \\
Strain & $N o n e$ & $\phi_{\varepsilon}$ & 1 \\
Stiffness & $E$ & $N / m$ & $\phi_{K}$ & $N$ \\
Damping & $K$ & $N . s / m$ & $\phi_{C}$ & $N^{2}$ \\
Frequency & $C$ & $H z$ & $\phi_{f}$ & $1 / N$ \\
Time & $f$ & $s$ & $\phi_{t}$ & $N$ \\
Velocity & $t$ & $m / s$ & $\phi_{V}$ & 1 \\
Acceleration & $v$ & $m / s^{2}$ & $\phi_{a}$ & $1 / N$ \\
Friction coefficient & $a$ & $N o n e$ & $\phi_{\mu}$ & 1 \\
\hline & $\mu$ & & & \\
\hline
\end{tabular}


and rail profile UIC54E1) down to the scale of five. The material parameters for the modelling purpose are listed in Table 4. The diameter of the rail ring in all the three alternatives was tentatively set to $4 \mathrm{~m}$. It is noteworthy that the proposed parameters and geometries are the nominal data obtained based on the scaling law. These parameters are used for the comparing the alternatives and for the concept design. It should be noted that these quantities need to be practically refined in the engineering design process for the ease and feasibility of manufacturing.

\section{Numerical Modelling of the Wheel-Rail Contact in the New Test Rig}

The wheel-rail contact problem in the test rig can be simulated using finite element (FE) modelling. The FE models of the three alternatives (test rig models) and the reference case (the actual wheel-rail system) are shown in Fig. 4. The contact occurs in the lateral centre of the railhead against the wheel tread. The sprung mass, which together with the unsprung mass (the wheel) forms the wheel load, was lumped and supported by a group of springs and dampers of the primary suspension. The loading condition was considered identical for the three alternatives (536 kg sprung mass applied on the wheels). The contact surfaces of both the wheel and the rail were smooth.

As mentioned before, having stresses and strains close to the real system is one of the major requirements on the new test rig, so as to reproduce RCF of the same nature as in the actual system. In order to estimate the level of contact stresses and strains, the solutions of the wheel-rail rolling contact problem were determined for the three alternatives. The modelling procedure with FEM and its validation against Hertz and Kalker solutions were previously reported in [42]. The results of FE simulations in this research are summarized in Table 5. The outputs of the simulations for the actual wheel-rail model (Fig. 4(d)) were consistent with those of [42]. Furthermore, the maximum pressures of the wheel-rail contact problem were calculated using the Hertz theory for comparison. These results are given in Table 5 together with the differences between FEM and Hertz theory in each case. The last column of the table presents the results of the actual wheel-rail components as a reference.

As shown in Table 5, the size of the contact patch was very much reduced by a factor of $\mathrm{N}^{2}\left(=5^{2}\right)$. The precise ratios of the contact area relative to the actual case were respectively 24.2 , 23.8 and 24.5 for the given alternatives. The contact pressures were close to the actual case; the differences in the three alternatives were respectively $4.4 \%, 6.1 \%$ and $3.3 \%$ compared to the actual case. The differences in the contact area and stress are negligible. These are caused by the mesh discretization in the model and by the curvature of the rail ring in the vertical or lateral direction, depending on the alternatives. In summary, all three alternatives offered closely comparable results and no significant distinction can be made in this respect.

\section{Numerical Modelling of the Rail Bending in the New Test Rig}

The downscale rail profile needs to be bent to create the curvature required for the various alternatives. This can be achieved by driving the rail through a suitable configuration of three steel rollers known as the roller-bending method [56, 57]. Residual stresses may arise during this process. The residual stresses were estimated by simulating the bending process with FEM. The FE models corresponding to the three alternatives are shown in Fig. 5(a, b, c). The FE models provided in this section are static simulations to calculate the stresses that can be generated during the roller-bending process. The results of the equivalent von-Mises stress due to
Table 4 Values of parameters used for wheel-rail materials in numerical simulations

\begin{tabular}{llll}
\hline Parameter & Value in actual railway & Scale factor & Design values in the test rig \\
\hline Young's modulus of material, $E$ & $210 \mathrm{GP}$ & 1 & $210 \mathrm{GP}$ \\
Poisson's ratio of material, $\nu$ & 0.3 & 1 & 0.3 \\
Density of material, $\rho$ & $7800 \mathrm{~kg} / \mathrm{m}^{3}$ & 1 & $7800 \mathrm{~kg} / \mathrm{m}^{3}$ \\
Lumped sprung mass, $M_{c}$ & $13.4 \mathrm{t}$ & $\mathrm{N}^{2}=25$ & $536 \mathrm{~kg}$ \\
Wheel diameter, $\phi$ & $920 \mathrm{~mm}$ & $N^{2}=5$ & $184 \mathrm{~mm}$ \\
Wheel mass, $M_{w}$ & $900 \mathrm{~kg}$ & $\mathrm{~N}^{3}=125$ & $7.2 \mathrm{~kg}$ \\
Friction coefficient, $\mu$ & 0.5 & 1 & 0.5 \\
Stiffness of primary suspension, $K$ & $1150 \mathrm{kN} / \mathrm{m}^{2}$ & $\mathrm{~N}=5$ & $230 \mathrm{kN} / \mathrm{m}$ \\
Damping of primary suspension, $C$ & $2500 \mathrm{~N} \mathrm{~s} / \mathrm{m}^{2}$ & $\mathrm{~N}^{2}=25$ & $100 \mathrm{~N} \mathrm{~s} / \mathrm{m}^{4}$ \\
Rail vertical moment of inertia, $I_{x x}$ & $2,337,900 \mathrm{~mm}^{4}$ & $\mathrm{~N}^{4}=625$ & $37,406 \mathrm{~mm}$ \\
Rail bottom section modulus, $S_{b o t}$ & $311,181 \mathrm{~mm}^{3}$ & $\mathrm{~N}^{3}=125$ & $2489 \mathrm{~mm}$ \\
Rail top section modulus, $S_{\text {top }}$ & $278,753 \mathrm{~mm}^{3}$ & $\mathrm{~N}^{3}=125$ & $2230 \mathrm{~mm}^{3}$ \\
Rail lateral moment of inertia, $I_{y y}$ & $4,192,000 \mathrm{~mm}^{4}$ & $\mathrm{~N}^{4}=625$ & $6707 \mathrm{~mm}^{4}$
\end{tabular}




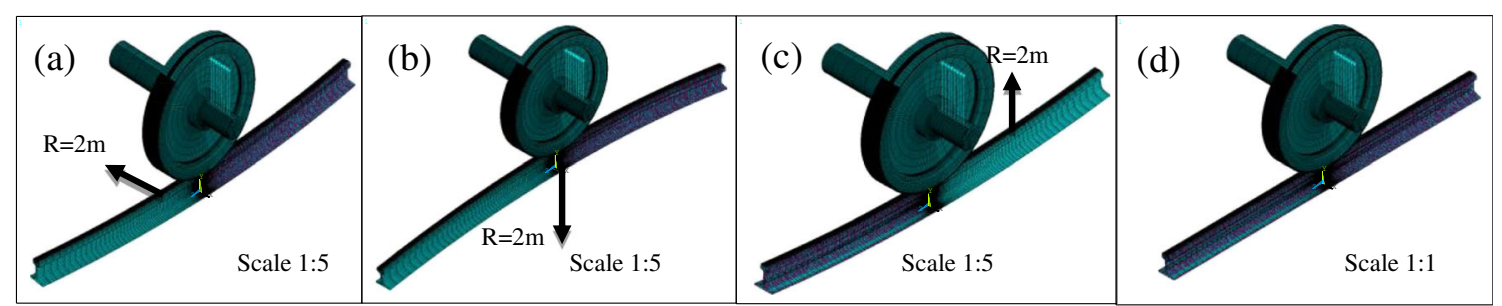

Fig. 4 3D FE models of the wheel-rail contact in different alternatives, a Alt-1, b Alt-2, c Alt-3 and the actual railway as the reference case d; arrows with $R=2 \mathrm{~m}$ show directions of the rail curvature in different cases

bending are presented in Fig. 5(d, e, f). These stresses were generated during the rail bending to $4 \mathrm{~m}$ diameter.

The residual stresses will remain in the rail because the rail is permanently deformed with the prescribed curvatures. Since the rails are intended for RCF experiments, residual stresses can have an unwanted influence on the test results. It is desirable to have low residual stress in the railhead and particularly in the running band. To examine this in the different alternatives, the stresses were determined for the most critical or characteristic locations at six elements. Four elements were chosen in the railhead (see 1 to 4 in Fig. 5(i)) and two extra elements in the middle and the edge of the railfoot $(5,6$ in Fig. 5(i)). A summary of the maximum von-Mises stresses at these elements is reported in Table 6 for all the three alternatives. Looking at Von-Mises stresses in Table 6, a significant difference is seen between the modelled alternatives. As can be seen there, significantly high stresses occurred in Alt-2 and 3 in the rail surface (elements 1-3). The peak stresses were seen in the middle of running band (element 1 ) for both alternatives. In contrary, Alt-1 had the least stress magnitude in this element $(153 \mathrm{MPa})$, which is lower than the yield stress of a typical rail material. According to the results in elements 1-3, Alt-1 introduced the least stresses in the running band. The greatest stress for Alt-1 was seen at the edge of rail foot. This is of less importance as the focus in the test rig is to study the wheel-rail contact interface where RCF occurs. Nevertheless, adequate care is taken in the design process to ensure that the fatigue at the edge of the rail foot will not affect the testing.
The numerical modelling of the rail bending process suggests an encouraging advantage for Alt-1, in which the railhead and especially the running band are less subjected to residual stresses. The numerical model of this section does not consider the time-dependent stress relaxation in materials when the rail is released from the roller-bending machine. It assumes that the obtained residual stresses will remain in the rail; because the rail is permanently deformed. This is indeed a conservative assumption since in reality part of these stresses will be relieved by time.

\section{Summary of the Comparisons and Final Choice for the Test Rig}

So far, a numerical approach was used to evaluate the mechanical performance of the different alternatives. In addition to these factors, the alternatives can be further evaluated based on several qualitative criteria. An overview of these aspects is summarized here.

\section{Rail track stability}

The importance of incorporating a track system with its detailed components into the test rig was shown before. A conventional railway track is composed of discrete components with no adhesion force between them, particularly with and between the ballast gravels which cannot sustain tensile stresses. A horizontal track system (Alt-1 of Fig. 3) is thus more
Table 5 Results of normal contact problem by FE simulation for different alternatives

\begin{tabular}{llllll}
\hline Parameters/Alternatives & Unit & Alt-1 & Alt-2 & Alt-3 & Actual condition \\
\hline Wheel radius & $R 1(\mathrm{~mm})$ & 92 & 92 & 92 & 460 \\
& $R 2(\mathrm{~mm})$ & $\infty$ & $\infty$ & $\infty$ & $\infty$ \\
Rail radius (ring/head) & $R 1(\mathrm{~mm})$ & $\infty$ & -2000 & 2000 & $\infty$ \\
& $R 2(\mathrm{~mm})$ & 70 & 70 & 70 & 300 \\
Vertical Load & $N$ & 5360 & 5360 & 5360 & 134000 \\
Semi-radius in FEM & $a(\mathrm{~mm})$ & 1.3 & 1.29 & 1.31 & 6.03 \\
& $b(\mathrm{~mm})$ & 1.54 & 1.58 & 1.51 & 8 \\
Contact area & $m m^{2}$ & 6.26 & 6.38 & 6.19 & 151.55 \\
Max. pressure FEM & $M P a$ & 1284.4 & 1261.5 & 1300.1 & 1344 \\
Max. pressure Hertz & $M P a$ & 1299.5 & 1278.3 & 1319.1 & 1364.7 \\
Difference FEM/Hz theory & $\%$ & 1.18 & 1.33 & 1.46 & 1.54 \\
\hline
\end{tabular}




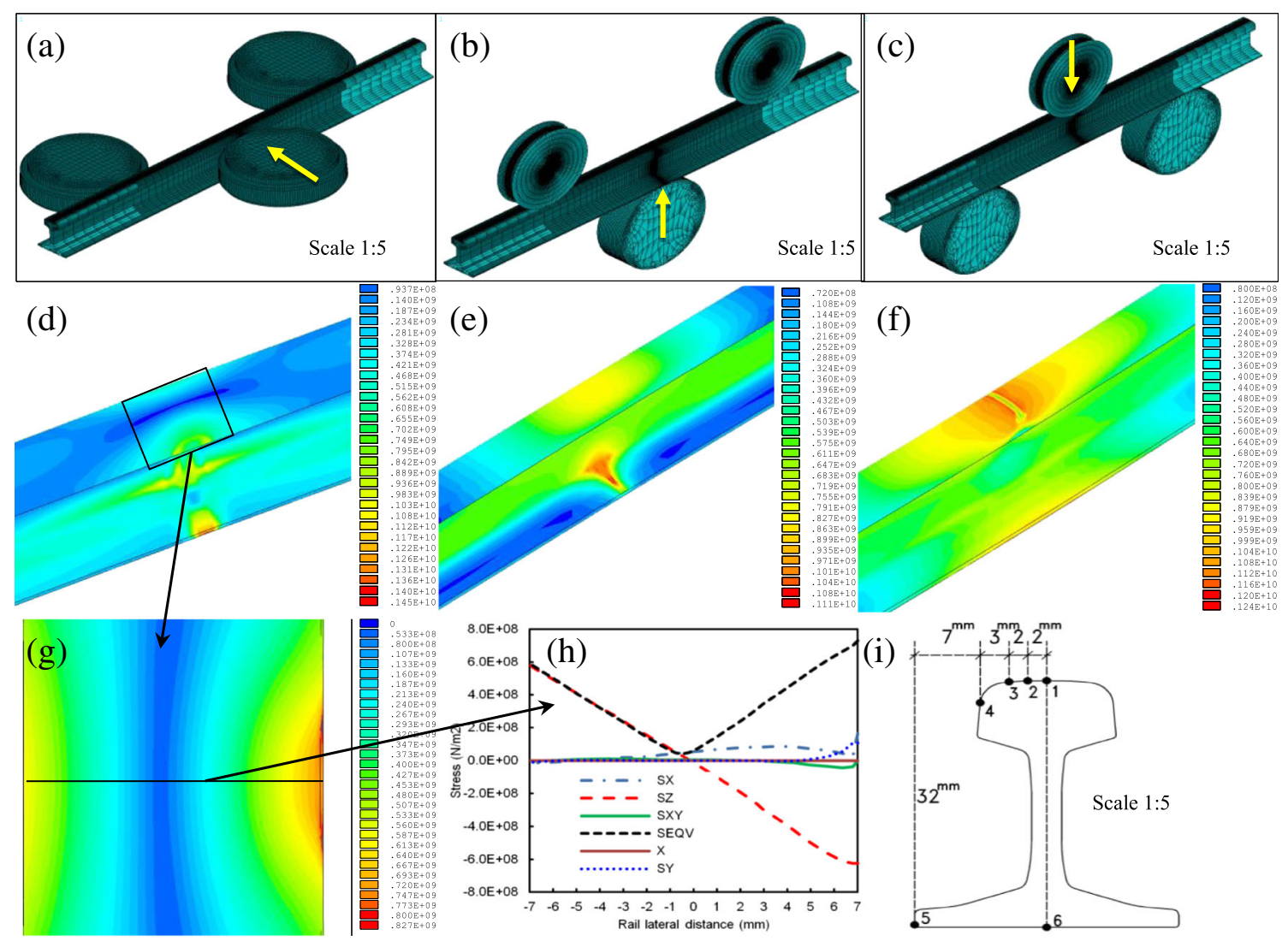

Fig. 5 3D FE models of the rail bending process for the three alternatives, a Alt-1; b Alt-2; $\mathbf{c}$ Alt-3; arrows show the directions of movement in rollers; $(\mathbf{d}, \mathbf{e}, \mathbf{f})$ Von-Mises stress contour plots generated during the bending process in different FE models; $\mathbf{g}$ closer view of the rail surface stress in Alt-1; $\mathbf{h}$ variation of the stress components in the 2D lateral view; $\mathbf{i} 6$ elements are selected in the rail cross section for reporting the stresses

stable than Alt-2 and 3 as the ballasted railway track with its typical form will be preloaded by the gravity loads from the vehicle. This can provide the test rig with higher stabilities, more durable geometrical conditions, a higher level of safety and closer similarity to the actual railway track.

\section{Analogy of loading conditions to the actual railway}

For the scaled alternatives, the wheel needs to be preloaded on the rail to achieve the required normal load. In most test rigs with the configuration of Alt-2 or Alt-3, the wheel remains static under the applied load and the rail (or the track) rotates under it. Such loading mechanism and that of the real life are

Table 6 Summary of the maximum V-M stresses for the three alternatives (all stresses in MPa)

\begin{tabular}{lllllll}
\hline Element location & 1 & 2 & 3 & 4 & 5 & 6 \\
\hline Alt-1, Fig. 5(a) & 153 & 242 & 354 & 965 & 1449 & 118 \\
Alt-2, Fig. 5(b) & 823 & 817 & 796 & 589 & 508 & 1115 \\
Alt-3, Fig. 5(c) & 1241 & 1169 & 1085 & 764 & 938 & 914 \\
\hline
\end{tabular}

somewhat unequal, particularly in connection with the vibrations that are generated in the vehicle and track subsystems. Such loading mechanism can be suitable for quasi-static analysis of the wheel-rail contact problem, while the loading mechanism of Alt-1 better represents the dynamic nature of the system. Another operational mechanism for Alt-2, 3 is the case where the wheel rotates around the vertical track drum. In this case, the direction of the normal load constantly changes during the wheel rolling in Alt-2,3. Hence, the control of the wheel preload in Alt-2, 3 is apparently more complicated. Furthermore, the wheel-rail contact pressure in Alt-2 and 3 changes when the wheel is running. In contrary, when the wheels continuously roll over rails in an actual railway (also the case of Alt-1), a constant normal force is present between the wheel and rail, if the dynamics of the wheel-track system is ignored. For Alt-1, that utilizes a horizontal track bed, the normal load is applied only in a single direction (the gravity direction) and this direction remains constant during the operation.

A similar discussion applies to the longitudinal loading (traction/braking efforts). Taking all these factors into account, important operational benefits can be seen for Alt-1. 
Table 7 Summary of comparison of the three alternatives

\begin{tabular}{ll}
\hline Criteria & Comparison of the three alternatives \\
\hline $\begin{array}{l}\text { Contact stresses and contact } \\
\text { patch size } \\
\begin{array}{l}\text { Residual stress levels in } \\
\text { the railhead }\end{array}\end{array}$ & $\begin{array}{c}\text { A slight difference was observed. No strong prioritisation can be proposed. } \\
\text { A clear distinction was found. Alt-1 offers a substantial benefit of } \\
\text { significantly lower residual stresses in the railhead and the running } \\
\text { band due to rail bending. }\end{array}$ \\
$\begin{array}{l}\text { Rail track stability, analogy } \\
\text { in loading conditions }\end{array}$ & $\begin{array}{l}\text { Alt-1 offers significant advantages in rail track stability and analogy of } \\
\text { loading conditions to the actual system owing to its horizontal track } \\
\text { bed configuration. }\end{array}$ \\
\hline
\end{tabular}

\section{Final choice for the test rig}

In view of the above discussion, the first alternative (a rotating wheel on a horizontal track bed) offers more benefits and shows a better potential performance than the other two. A summary of its advantages is listed in Table 7. Based on this evaluation, the operational mechanism of the first alternative is chosen for the new test rig.

According to the chosen mechanism, detailed numerical modelling and mechanical calculations were carried out to finalise the structural design of the new setup. The test rig has been engineered with an overall scale of 1:5 (basic scale), providing the flexibility of having smaller or bigger wheeltrack elements. The CAD view of the setup after the engineering work is shown in Fig. 6, with the nomination of the major components underneath the figure. It is capable of testing materials of rails and wheels under loading conditions equivalent to the actual operations. As can be seen in Fig. 6, the rig is a rotating frame structure with four wheels running on a fixed rail track bed, capable of simulating continuous wheelrail contact.

The setup is constructed through a rigorous engineering design and manufacturing process, involving the professional expertise of various fields in mechanics, mechatronics, electronics, control, safety, etc. Analogical components of the wheel-track system are made and assembled, maintaining dynamic behaviours of the tests with similarity to real vehicletrack systems including the scalability analysis described in this paper. Fig. 7 shows the newly-built setup, established on a firm fundament in the laboratory. The track bed in Fig. 7 consists of a scaled rail connected to the wooden sleepers using elastic fasteners. The ballast in the current configuration is replaced by rubber materials with the required damping/ stiffness properties. It can also be made of crushed stone as enough space is provided by the track container to hold the ballast and allow for tamping. The wooden sleepers can also be replaced by concrete sleepers depends on the test goals. The rail is supported by the sleepers in lateral, longitudinal and vertical directions. The sleepers can be constrained in any combinations of the three directions by connecting them to the track container with the desired stiffness and damping.

Having a curved track in the setup is the most important dissimilarity factor between the setup and the real life. However as stated in "The Ring Track Mechanism" section, this is the most effective way that provides a continuous longterm rolling contact between the when and rail. Due to the same reason, the majority of the existing test rigs in the literature have used the curved track principle. In order to
Fig. 6 The $C A D$ view of the final test rig after detailed engineering design

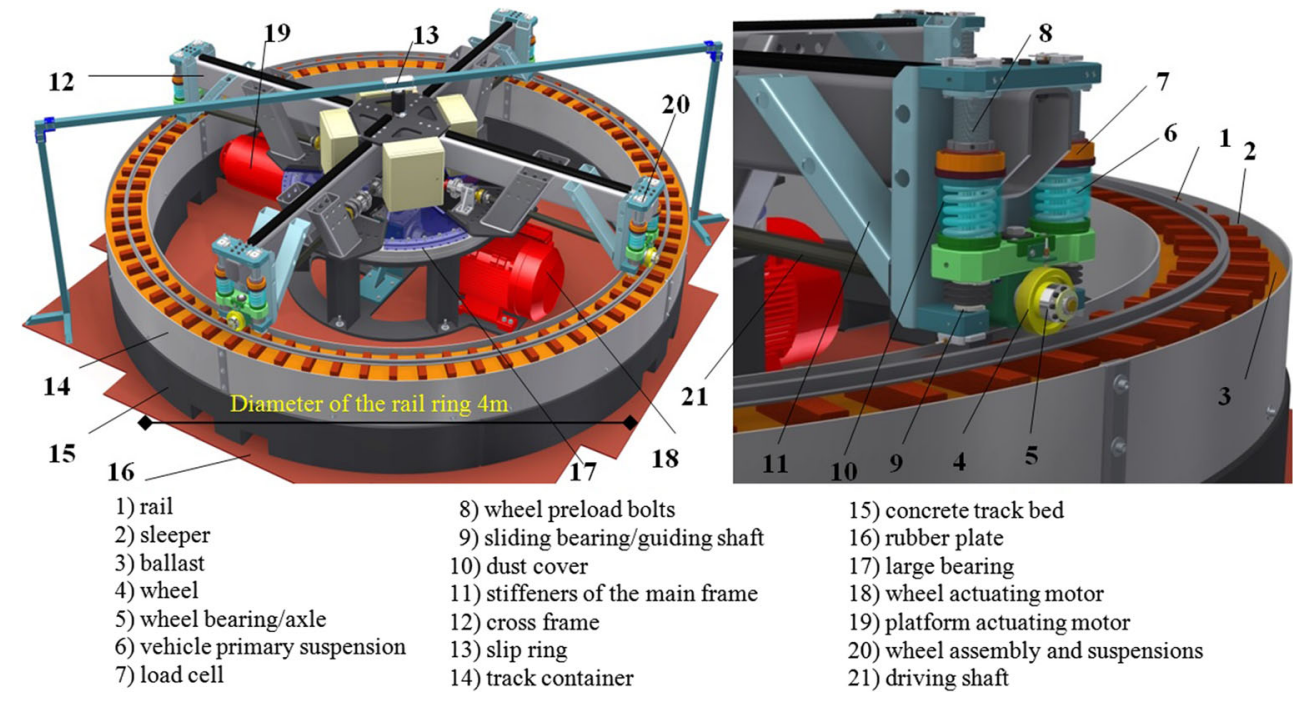



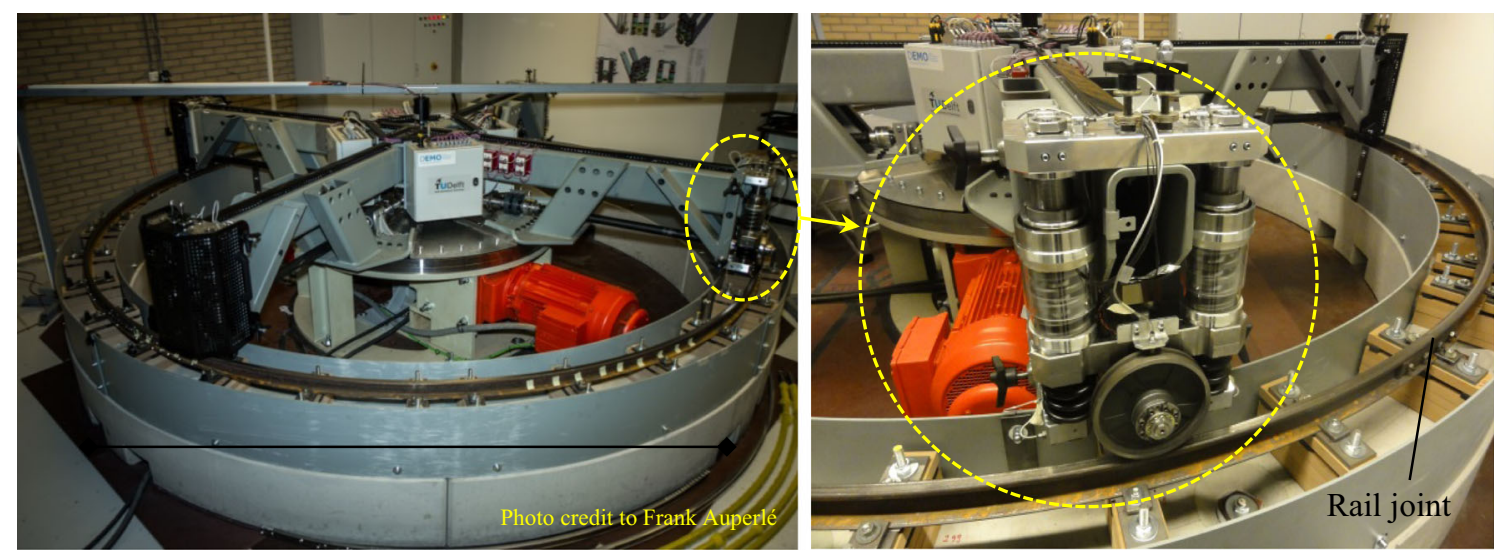

Fig. 7 The newly-built test rig for the wheel-rail contact studies; each of the four wheel-assemblies can be activated or dismantled from the frame

minimize the effect of having a curved track in the test configuration the following treatments can be provided in the setup:

- For testing squats (involving the vertical high-frequency vibrations) the wheels do not necessarily have the flange and the contact occurs in the middle of the railhead. Therefore, gauge corner contact will be avoided. Any effects of the curved setup on the similarity with the straight track will be studied, identified and removed for any specific tests. Numerical analysis and physical testing can be used for this purpose; possible approaches are briefly demonstrated below in "FE Modelling And Experiments Using The Newly-Built Test Rig" section. For testing head-checks, flanged or conical wheels can be used, where gauge corner contact can occur.

- By offsetting the centre of the rail ring, the position of the running band of the wheels will vary with the offset along the ring.
- To avoid conformal contact, the wheels will be re-profiled or changed after certain contact cycles if they are highly worn.

- The rail circle diameter has been selected relatively large (4 m) to have sufficiently low residual stresses during the rail bending (see "Numerical Modelling of the Rail Bending in the new Test Rig" section).

From the engineering point of view, a diameter larger than $4 \mathrm{~m}$ was not feasible because the moving subsystem (wheels, driving shafts, frames and all their attached components) will exert extremely high electro-mechanical demands on safety and on the strength of some components.

\section{Description of the new test rig}

As can be seen in Figs. 6 and 7, the four wheel assemblies are mounted on a stiff frame (the platform). This platform is fixed to the inner ring of a large bearing (17 in Fig. 6) and drives by

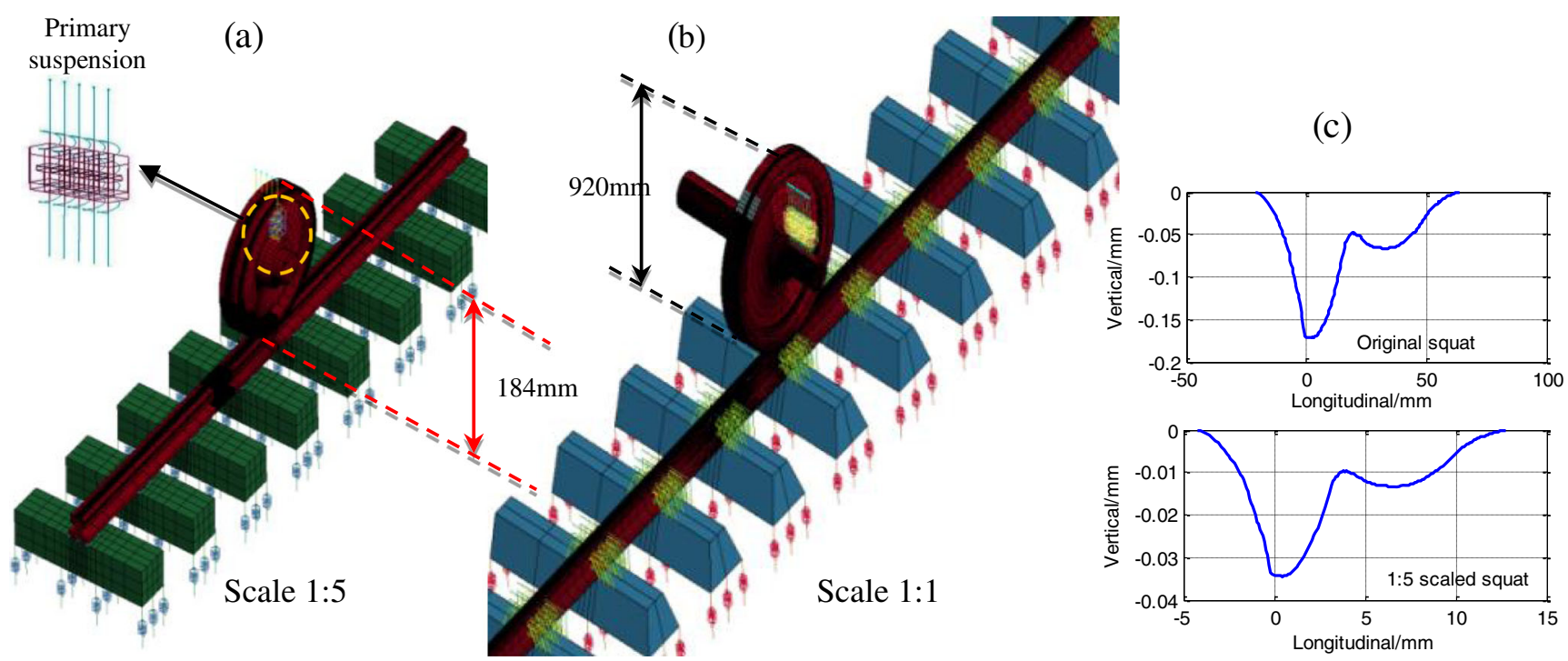

Fig. 8 a A FE model of the 1:5-scaled test rig to study its dynamic behaviours; $\mathbf{b}$ the FE model of the actual wheel-track system, the wheel diameters $(184$ and $920 \mathrm{~mm})$ are shown as per indication of the scale; $\mathbf{c}$ the geometry of an original real-life squat and its equivalent defect with the scale of $1: 5$ 
Fig. 9 The normalized wheel-rail contact forces in the FE models with a smooth rail; $\mathbf{b}$ squat defect
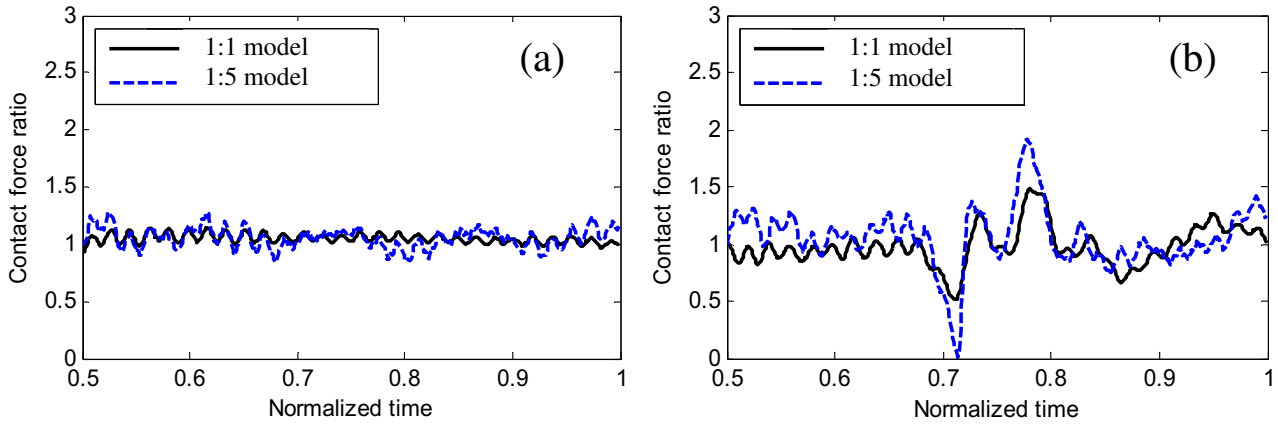

the platform motor (19 in Fig. 6). The outer ring of this bearing is fixed using a frame to the ground. The wheels are driven by the wheel motor (18 in Fig. 6). This motor is coupled with two gearboxes that transfer and divide the power to the wheels.

The combination of these two motors (18 and 19) generates traction or braking forces at the wheel rail contact and maintains the required speed. The power from the wheel motor is transferred with a gearbox from rotation around the horizontal axis to a rotation around the vertical axis. With a second gearbox, the rotation around the vertical axis is transferred with a factor of $1 / 4$ to the rotation around the horizontal axis on each wheel shaft. The power from the platform motor is used to drive an internal gear that is mounted on the large bearing. When the wheel motor is driving, one can use platform motor to let the wheels slip relative to the rail. When the platform motor is driving, one can use the wheel motor for braking the wheels. With such mechanism, the driving and braking possibilities can be provided for the wheels under the desired creepage with the traction coefficient variable between 0 and 0.45 .

The wheels are mounted on the rail using the springdamper assemblies (20) with adjustable loading mechanism equivalent to the primary suspension of a train. The vertical static preload on the wheels is adjusted by preloading the two springs (6) between the wheel axle (5) and the cross-frame above it (12). The wheels can be cylindrical or conical depending on the test requirements. The wheel angle of attack is adjustable between $-2^{\circ}$ and $+2^{\circ}$.

Depending on the scope of each testing scenario, one would be able to study various degradation topics: (1) about the rail e.g. wear, squat, head-check, weld effect, joint effect; (2) about the wheel e.g. wheel flat, unrounded wheel; and (3) about the other track components, e.g. loose or damaged fasteners, worn railpads, unsupported sleepers, polluted ballast etc..

\section{FE Modelling and Experiments Using the Newly-Built Test Rig}

This section presents some results on estimating and measuring the high-frequency vibrations in the newly-built test rig. For this purpose, some output of FE modelling and real measurements with the newly-built setup is provided. A transientfinite element model of the wheel-track contact was built according to the geometry and loading conditions of the 1:5scaled setup; see Fig. 8(a). The FE calculations provided in this section are dynamic simulations to compare the numerical results with the experimental results; in these FE models, a wheel component runs with the given speed over the track. The material specifications and loading parameters were assumed according to Table 4 . As given in Table 5, the contact stresses and the patch size are only slightly different for the curved rail. Hence, a straight rail track is modelled. The parameters of the sleepers, fastenings and ballast in the FE model were calculated by the scaling factors in Table 3. For the purpose of comparison, a finite element model of the actual wheel-track system (full-scale) was also built; see Fig. 8(b).

\section{FE Modelling with Squat Defect}

A typical squat with W-shape profile [58] was applied on the rail surface of the full-size model. Applying the linear scale
Fig. 10 The normalized contact forces, a smooth rail; $\mathbf{b}$ with rail joint; comparison between the test rig model (scale 1:5) and real measurements in the test rig with preliminary wheel-track components of various scales between $1: 3$ and $1: 5$
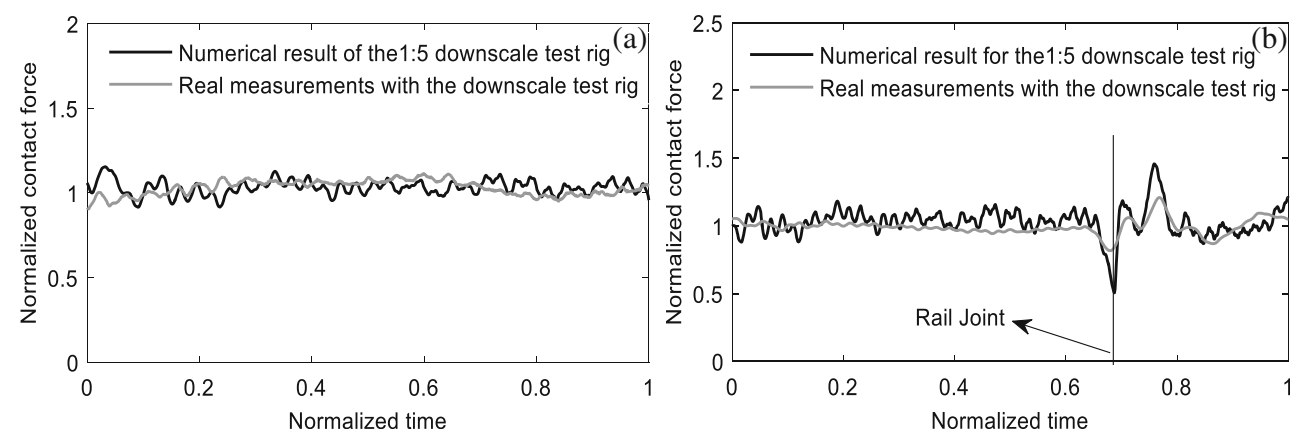


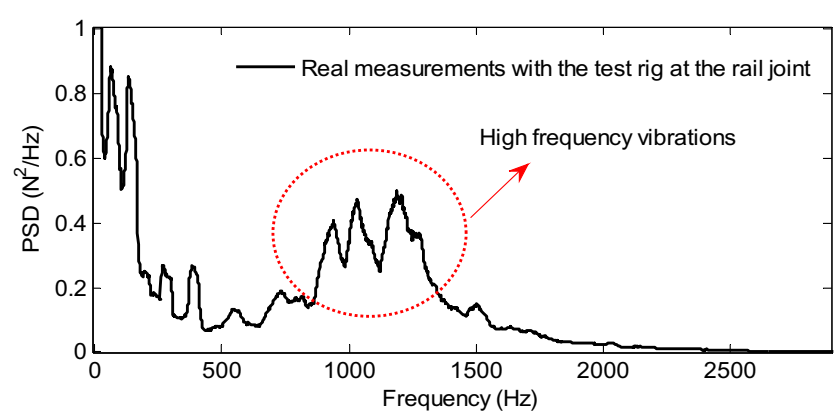

Fig. 11 The frequency content of the contact force measured in the test rig with rail joint

factor of 1:5 on the defect geometry, an equivalent defect was applied on the 1:5-scaled model. Fig. 8(c) shows the longitudinal-vertical profiles of the original and the scaled squats.

Considering these defects, dynamic simulations were carried out for the 1:1 and 1:5 models. The time history of the wheel-rail contact forces for the smooth rails and for the rails with the prescribed squats are shown in Fig. 9. The abscissas in these figures are normalized relative to the maximum simulation times in each model to obtain comparable data. The vertical axes show the dynamic load ratios relative to the corresponding static values (dynamic amplification factors). As can be seen in Fig. 9, the dynamic amplification factors under the presence of squats were increased in both the full-scale and scaled models.

\section{FE Modelling and Experiments of the Rail Joint}

To study the dynamic behaviour of the scaled test rig in the presence of the impact-induced RCF, a typical insulated rail joint in the Dutch railway system was considered. A similar rail joint (with the scaled size) was constructed in the newlybuilt test rig; Fig. 7(b). To evaluate the dynamic behaviour of the rig, trial tests were performed with the running speed of $20 \mathrm{~km} / \mathrm{h}$, wheel diameter of $200 \mathrm{~mm}$, the standard rail profile of S7 and the static load of $1.3 \mathrm{kN}$ on the wheel. The wheel-track components were made for the preliminary tests and were not precisely according to the required scale factors. The components in such a preliminary wheel-track setup were downsized with various scales between 1:3 and 1:5 relative to the real system.

Using a transient finite element approach [42], the rolling contact process of the wheel over the rail is simulated for the downscale test rig, shown in Fig. 8(b). To consider the effect of rail joint, a $2 \mathrm{~mm}$ rail gap was considered in the finite element model of the test rig rail.

The time histories of the wheel-rail contact force are given in Fig. 10, for the smooth rail and for the rail with the joint. For the sake of comparison, the abscissas in these figures were normalized relative to the whole duration of the simulation or the measurement. The vertical axes show the dynamic load ratios relative to the corresponding static loads. The contact force between the wheel and rail are measured using a real-time data acquisition system in the test rig.

It can be seen from Fig. 10 that the contact force obtained from the modelling is in good agreement with the measured forces in the test rig with or without the presence of the rail joint. The frequency content of the normal contact force is calculated using Fast Fourier transformation (FFT); see Fig. 11. The major high-frequency content is around $1.1 \mathrm{kHz}$, which agrees with the high-frequency ranges obtained for the real track [59], where measurements of similar cases were presented. These findings confirm that the setup is able to represent high-frequency dynamic characteristics of the wheel-rail contact system.

In order to further evaluate the dynamic performance of the test rig, the setup has been under operation using the trial wheel-rail pairs (wheel diameter $200 \mathrm{~mm}$ and the standard rail profile S7). The speed varied between 0 and $40 \mathrm{~km} / \mathrm{h}$ and the static preload on the four wheels was around $1.3 \mathrm{kN}$. The running bands on the rail and wheels were frequently inspected during the test intervals. After around 41,300 revolutions (in total 165,200 wheel-rail contact cycles, as four wheels were activated) some changes were observed on the rail surface. A potential rail corrugation, shown in Fig. 12(b), started to develop after the rail joint. Fig. 12(a) shows an example of corrugation wave pattern that occurred close to a real joint in a straight track in the Dutch railway network. Looking at the wave pattern of the potential corrugation in Fig. 12(b) and its proximity to the rail joint, the similarity with the real-life corrugation (Fig. 12(a)) is remarkable. Such a wave pattern was only seen after the rail joint, hence it can be hypothesised that it is generated due to the dynamic impact induced by the rail joint; see the impact in Fig. 10(b). RCF defects can be the consequence of corrugations due to the high loads occurred at corrugation [60]. RCF can also be a cause of corrugation as it was suggested by $[61,62]$. The damage mechanism for many RCF and corrugation defects is the
Fig. 12 a An actual corrugation after the rail joint in the Dutch railway network; $\mathbf{b}$ a potential corrugation after the rail joint in the new test rig with preliminary wheel-track components of various scales between $1: 3$ and 1:5
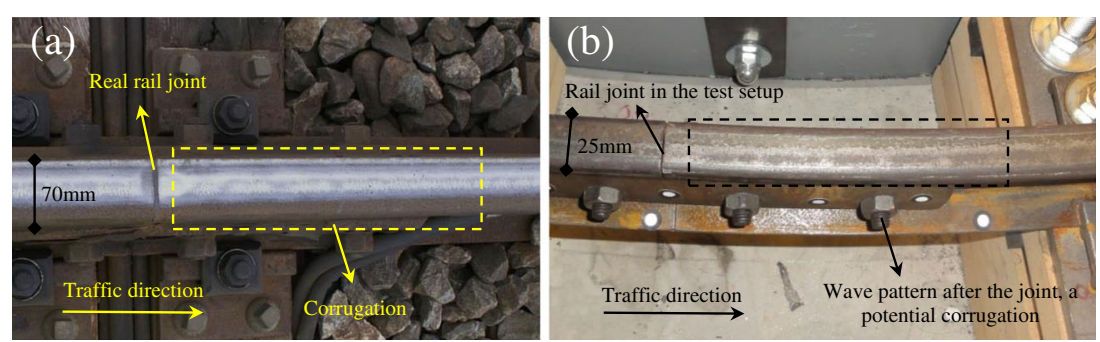


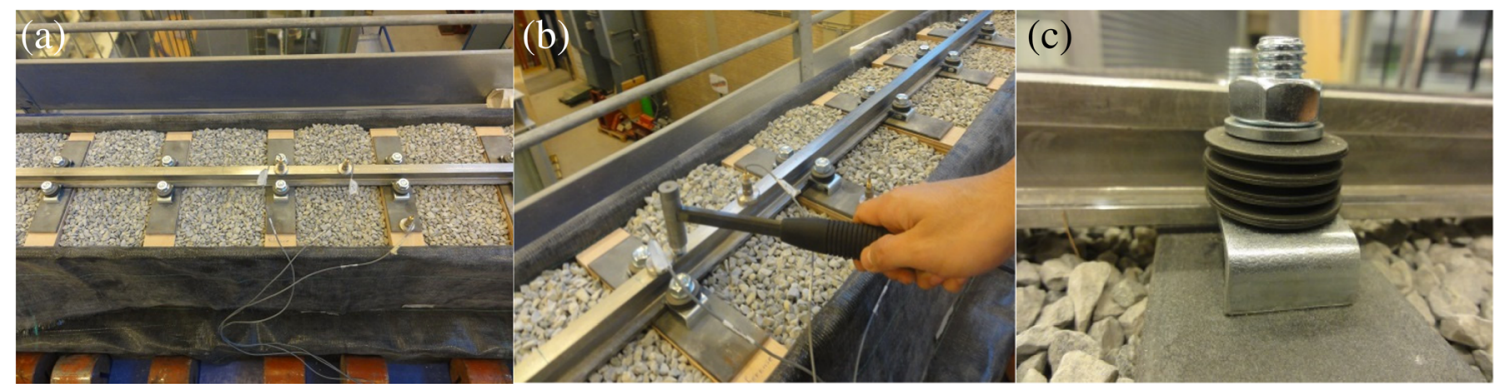

Fig. 13 a A 1:5 downscale ballasted railways track; $\mathbf{b}$ hitting the rail surface using an instrumented impact hammer; $\mathbf{c}$ magnified view of the designed fastening system for fixing the rail on sleepers

high-frequency vibration of the wheel-track system, which can be studied using the new test rig. These observations further confirm that the new test rig is able to generate the impactinduced defects in rails, as it was predicted in the design process.

\section{Scalability of Track Dynamic Characteristics by Impact Measurements}

In order to investigate the scaling effect on the dynamic behaviour of the track system, a prototype ballasted railway track is built in the lab with the scale of 1:5 (Fig. 13). The components of the scaled track system were designed and made with the specifications given in Table 8. Dynamic hammer test measurements were carried out on the scaled test track. Dynamic excitations were generated using a $160 \mathrm{~g}$ instrumented impact hammer. The hammer hits the rail surface at different locations relative to the sleepers, i.e. on top of the sleepers (on support) and at the middle spans; see Fig. 13(b). Two accelerometers were mounted on the railhead (one on support and another one on the midspan) to record the dynamic responses in the track induced by the impact hammer.

Hammer test measurements were carried out with hitting the railhead vertically at locations above the sleepers and at
Table 8 Specifications of the track components used in the 1:5 downscale ballasted railways track

\begin{tabular}{|c|c|}
\hline Track component & Specifications \\
\hline Rail & $\begin{array}{l}\text { - A } 1: 5 \text { scaled profile based on the standard UIC54E1 profile } \\
\text { - Height } 30 \mathrm{~mm} \text {, railhead depth } 8 \mathrm{~mm} \text {, railhead top curve radius } 60 \mathrm{~mm} \text {, railhead } \\
\text { width } 18 \mathrm{~mm} \text {, railfoot width } 28 \mathrm{~mm} \\
\text { - Weight: } 2.95 \mathrm{~kg} / \mathrm{m} \\
\text { - Cross section: } 378 \mathrm{~mm}^{2} \\
\text { - Moment of inertia } \mathrm{I}_{\mathrm{xx}}: 3970 \mathrm{~mm}^{4} \\
\text { - Bending stiffness: } 8337 \mathrm{Nm}^{2}\end{array}$ \\
\hline Sleepers & $\begin{array}{l}\text { - A 1:5 scaled profile based on the standard B93.1 sleeper } \\
\text { - Material: a mix of wood and steel with the scaled weight } \\
\text { - Dimensions: length } 250 \mathrm{~mm} \text {, width } 50 \mathrm{~mm} \text { and height } 40 \mathrm{~mm} \\
\text { - Sleeper weight: } 1250 \mathrm{~g} \\
\text { - Sleeper spacing: } 120 \mathrm{~mm} \text { (centre to centre) }\end{array}$ \\
\hline Fastening system & $\begin{array}{l}\text { - Materials: combination of steel bolts, spring washers, clips, bolts and washers } \\
\text { - Weight of the fasteners per sleeper } \approx 250 \mathrm{~g} \\
\text { - Spring washers: } 6 \text { per bolt in series }\end{array}$ \\
\hline Railpads & $\begin{array}{l}\text { - Materials: Natural rubber } \\
\text { - Size: length } 50 \mathrm{~mm} \text {, width } 28-30 \mathrm{~mm} \text { and height } 1-3 \mathrm{~mm} \text {; (height is adjusted to } \\
\text { reach the required stiffness) } \\
\text { - Stiffness of rail pad } \approx 50 \mathrm{kN} / \mathrm{m} \\
\text { - Damping of rail pad } \approx 2 \mathrm{kN} . \mathrm{s} / \mathrm{m}\end{array}$ \\
\hline Ballast & $\begin{array}{l}\text { - Materials: granite stone gravels } \\
\text { - Density of the compacted ballast } \approx 1551 \mathrm{~kg} / \mathrm{m} 3 \\
\text { - Size of gravels: ranging from } 4 \mathrm{~mm} \text { to } 21 \mathrm{~mm} \\
\text { - Stiffness of ballast } \approx 10 \mathrm{kN} / \mathrm{m} \\
\text { - Damping of ballast } \approx 1 \mathrm{kN} . \mathrm{s} / \mathrm{m}\end{array}$ \\
\hline
\end{tabular}


Fig. 14 Results of impact hammer measurements in the 1:5 downscale ballasted railways track

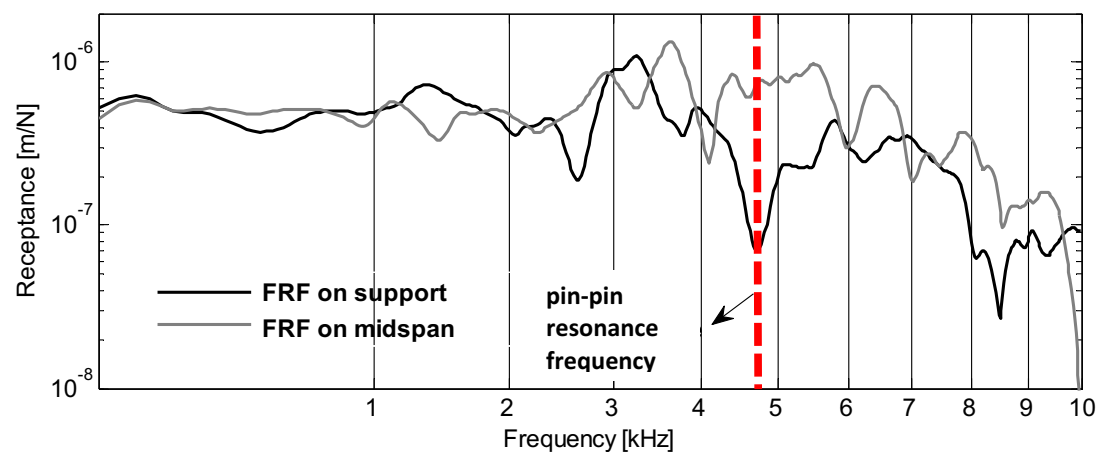

midspans. The track accelerance (acceleration for a unit force) is calculated during the impact excitations. The acceleration responses are measured at supports and at the midspans. The results of frequency response functions (FRFs) are shown in Fig. 14. This figure shows the characteristic frequencies of the track system under the mentioned impact loading. According to this figure, the pinned-pinned resonance frequency of the rail is around $4720 \mathrm{~Hz}$, which is marked using a thick vertical dash line. This frequency corresponds to the location where a local peak is found at mid-span FRF and a sharp dip is seen on FRF above the sleeper. This pin-pin frequency is approximately five times of the corresponding pin-pin frequency of the full-scale track reported in [63]. Due to the use of a scale factor of 5 , the track characteristic frequencies were approximately five times of those of the full-scale system; see the scale factor of the frequency parameter in Table 3. These results are in good agreement with results from another 1:5 scaled test track in [27] and further confirm the scalability potential of the developed downscale system with respect to dynamic characteristics.

\section{Conclusions}

A wide range of available test setups for wheel-rail contact experiments was classified and comparatively reviewed. Six categories were distinguished and their functionalities synthesised: 1) Full-size vehicle/ bogie, 2) Full-size wheel-on-roller, 3) Full-size wheel-on-straight, 4) Twin-discs, 5) Scaled wheel on rail track ring and 6) Scaled wheel on the straight track. The fifth category could better mimic the high-frequency dynamic behaviours of the system. Three conceptual alternatives were further analysed: Alt. 1) The wheel on a horizontal ring-track, Alt. 2) The wheel rolling on the outer side of a vertical track drum and Alt. 3) Rotating wheel on the inner side of a vertical track drum. According to the results, the following conclusions are drawn:

1- The rail curvature $(R=2 \mathrm{~m})$ in the different alternatives had negligible influence on the contact stresses and contact patch size.
2- Numerical simulations confirmed that Alt-1 in which the rail profile is bent about its vertical axis has significantly lower residual stresses (due to rail bending) in the running band of the railhead.

3- Alt-1 also offered significant advantages with respect to the rail track stability and analogy of loading conditions to the actual system.

4- Using transient finite element modelling, it was confirmed that the new test rig is capable of reproducing high-frequency dynamic characteristics of the wheeltrack system when a typical $\mathrm{w}$-shape squat is present on the railhead.

5- Dynamic effects induced by the presence of a rail joint were properly reflected in the downscale test rig. This was confirmed by transient finite element modelling and by real measurements using the newly built setup.

6- After about 41,300 preliminary test revolutions in the new test rig, some potential corrugation wave patterns were observed on the railhead, which considered to be generated by the impact due to the rail joint. The wave pattern of this was in good agreement with those of the real-life systems.

7- The scalability of dynamic characteristics of the system is confirmed by performing impact hammer test measurement on a prototype ballasted railway track with the scale of $1: 5$.

The new setup is, in fact, a rotating frame structure containing four wheels, running on a fixed ring-track bed, capable of simulating the continuous wheel-rail rolling interaction. It is designed and manufactured with the overall scale of 1:5 (basic scale), providing the flexibility of having smaller or bigger wheel-track elements. It is built through a rigorous engineering design and manufacturing process. This test rig will provide a worthy means for deeper insights into track degradation mechanisms and performance of rail and wheel materials under the impact loading comparable to real-life railway operation.

Acknowledgements Design and construction of the new test rig are part of an ExploRail project namely as Development of HighPerformance Rail through Intelligent Metallurgy and Engineering 
(PRIME) at Delft University of Technology. This project (Code: 11247/ C38A07) is funded by Dutch rail infra manager ProRail and the Netherlands organization for scientific research (STW/NWO). The help of Steve van Herk and Giel Hermans from DEMO and Jan Moraal from TU Delft for the engineering design, manufacturing and assembling of the new test rig is kindly acknowledged.

Open Access This article is distributed under the terms of the Creative Commons Attribution 4.0 International License (http:// creativecommons.org/licenses/by/4.0/), which permits unrestricted use, distribution, and reproduction in any medium, provided you give appropriate credit to the original author(s) and the source, provide a link to the Creative Commons license, and indicate if changes were made.

\section{References}

1. Ekberg A, Bjarnehed H, Lundbéan R (1995) A fatigue life model for general rolling contact with application to wheel/rail damage. Fatigue Fract Eng Mater Struct 18(10):1189-1199

2. Clayton P, Hill DN (1987) Rolling contact fatigue of a rail steel. Wear 117(3):319-334

3. Grassie, S and Kalousek J (1997) Rolling contact fatigue of rails: characteristics, causes and treatments. In Proceedings of 6th international heavy haul conference, The International Heavy Haul Association, Cape Town

4. Li Z et al (2011) Squat growth - some observations and the validation of numerical predictions. Wear 271(1):148-157

5. Franklin F et al (2005) Rolling contact fatigue and wear behaviour of the infrastar two-material rail. Wear 258(7):1048-1054

6. ASTM-STP771 (1982) Rolling contact fatigue testing of bearing steels. American Society for Testing and Materials

7. Thompson DJ, et al (2003) Railway noise: curve squeal, roughness growth, friction and wear. Real Research UK, Report RRUK/A3/1, June 2003. Available at http://civ-hrg.bham.ac.uk/ RailResearchUK/theme-a3.htm

8. Ma S et al (1994) Full scale roller rig simulation for railway vehicles. Veh Syst Dyn 23(S1):346-357

9. Alzaga X (2014) Manufacturing development, automatic machining and verification of railway running gears. In Second European Forum on Railway Running Gears, June 2014. Universidad de Alcalá de Henares - Rectorado, Madrid

10. Matsumoto A et al (2008) A new measuring method of wheel-rail contact forces and related considerations. Wear 265(9):1518-1525

11. Burstow MC (2006) Rolling contact fatigue laboratory testing, vol. AEATR-ES-2004-907, Issue 1, Report LD44089. Rail Safety and Standards Board (RSSB), London

12. Stock R, Pippan R (2011) RCF and wear in theory and practice-the influence of rail grade on wear and RCF. Wear 271(1-2):125-133

13. Deutsche-Bahn AG, Welte Druck GmbH (1994) The Roller Rig, Central Division for Research and Testing. Research and Test Centre 3, Munich-Freimann, Germany

14. Bruni S, Cheli F, Resta F (2001) A model of an actively controlled roller rig for tests on full-size railway wheelsets. Proc Inst Mech Eng, Part F: J Rail Rapid Transit 215(4):277-288

15. Knani K, et al. Development of an integrated design methodology for a new generation of high performance rail wheelset in World Congress of Railway Research WCRR

16. Zhang W et al (2006) Chapter 14, Roller Rigs. In: Iwnicki S (ed) Handbook of railway vehicle dynamics. CRC Press, Boca Raton

17. Allotta B et al (2013) Development of a HIL railway roller rig model for the traction and braking testing activities under degraded adhesion conditions. Int J Non Linear Mech 57:50-64
18. Monk-Steel AD et al (2006) An investigation into the influence of longitudinal creepage on railway squeal noise due to lateral creepage. J Sound Vib 293(3-5):766-776

19. De Beer F, Janssens M, Kooijman P (2003) Squeal noise of railbound vehicles influenced by lateral contact position. J Sound Vib 267(3):497-507

20. Liu Q, Zhang B, Zhou Z (2003) An experimental study of rail corrugation. Wear 255(7):1121-1126

21. Allen P, Iwnicki SD (2001) The critical speed of a railway vehicle on a roller rig. Proc Inst Mech Eng, Part F: J Rail Rapid Transit 215(2):55-64

22. Hsu SS, et al., (2007) Experimental and theoretical investigation of railway wheel squeal. Proc Inst Mech Eng, Part F: J Rail Rapid Transit, 221(1): p. 59-73

23. Vuong $\mathrm{T}$ et al (2011) Investigation of a transitional wear model for wear and wear-type rail corrugation prediction. Wear 271(1):287298

24. Docquier N, Fisette P (2011) A scaled-bogie test bench to understand and demystify wheel/rail contact dynamics. In: Multibody dynamics 2011-ECCOMAS thematic conference. Universite catholique de Louvain, Brussels, Belgium

25. Fletcher D, Beynon J (2000) Development of a machine for closely controlled rolling contact fatigue and wear testing. J Test Eval 28(4):267-275

26. Armstrong TD (2004) Measurements and predictions of wheel-rail vibration using a $1 / 5$ th scale rig. Ph.D thesis. University of Southampton, Southampton

27. Zhu J, Thompson D, Jones C (2011) On the effect of unsupported sleepers on the dynamic behaviour of a railway track. Veh Syst Dyn 49(9):1389-1408

28. Papaelias MP et al (2008) Detection and quantification of rail contact fatigue cracks in rails using ACFM technology. Insight-NonDestructive Test Cond Monitor 50(7):364-368

29. Heliot C (1986) Small-scale test method for railway dynamics. Veh Syst Dyn 15(sup1):197-207

30. Allen P (2006) Chapter 15, Scale Testing. In: Iwnicki S (ed) Handbook of railway vehicle dynamics. CRC Press, Boca Raton

31. Matsumoto A et al (2002) Creep force characteristics between rail and wheel on scaled model. Wear 253(1):199-203

32. Savkoor A, van der Schoor G (1993) Slip-time history influences on the interaction between friction and wear in contaminated rolling contacts of wheel-rail systems. Wear 162:980-984

33. Bruzelius K, Mba D (2004) An initial investigation on the potential applicability of acoustic emission to rail track fault detection. NDT\&E Int 37(7):507-516

34. Jin Y, Ishida M, Namura A (2011) Experimental simulation and prediction of wear of wheel flange and rail gauge corner. Wear 271(1):259-267

35. Takikawa M, Iriya Y (2008) Laboratory simulations with twin-disc machine on head check. Wear 265(9):1300-1308

36. Allotta B et al (2010) A scaled roller test rig for high-speed vehicles. Veh Syst Dyn 48(S1):3-18

37. de Pater, A. and Gu-Ang, Y (1991) The Geometrical Contact between a Pair of Rollers and a Wheelset in a Railway Vehicle Roller Rig, In Dynamical Problems of Rigid-Elastic Systems and Structures, Springer. p. 179-189

38. Torstensson PT, Nielsen JCO, Baeza L (2011) Dynamic train-track interaction at high vehicle speeds - Modelling of wheelset dynamics and wheel rotation. J Sound Vib 330(22):5309-5321

39. Nielsen JCO (2008) High-frequency vertical wheel-rail contact forces - validation of a prediction model by field testing. Wear 265(9-10):1465-1471

40. Grassie $\mathrm{S}$ et al (1982) The dynamic response of railway track to high frequency vertical excitation. J Mech Eng Sci 24(2):77-90 
41. Chaar N, Berg M (2006) Simulation of vehicle-track interaction with flexible wheelsets, moving track models and field tests. Veh Syst Dyn 44(sup1):921-931

42. Zhao X, Li Z (2011) The solution of frictional wheel-rail rolling contact with a $3 \mathrm{D}$ transient finite element model: validation and error analysis. Wear 271(1-2):444-452

43. Zhao X, Li Z, Liu J (2012) Wheel-rail impact and the dynamic forces at discrete supports of rails in the presence of singular rail surface defects. Proc Inst Mech Eng, Part F: J Rail Rapid Transit 226(2):124-139

44. Dollevoet R (2010) Design of an anti head check profile based on stress relief. Ph.D thesis, University of Twente, Enschede, The Netherlands

45. Jenkins H et al (1974) The effect of track and vehicle parameters on wheel/rail vertical dynamic forces. Railw Eng J 3(1):2-16

46. Knothe K, Grassie S (1993) Modelling of railway track and vehicle/ track interaction at high frequencies. Veh Syst Dyn 22(3-4):209262

47. Zhao X, Li ZL, Dollevoet R (2013) The vertical and the longitudinal dynamic responses of the vehicle-track system to squat-type short wavelength irregularity. Veh Syst Dyn 51(12):1918-1937

48. Zhao X, Li Z, Dollevoet R (2014) Influence of the fastening modeling on the vehicle-track interaction at singular rail surface defects. J Comput Nonlinear Dyn 9(3):031002

49. Thompson DJ, Verheij JW (1997) The dynamic behaviour of rail fasteners at high frequencies. Appl Acoust 52(1):1-17

50. Burstow M. (2011) Improving track geometry alignment to reduce rolling contact fatigue (RCF). In: Proceedings of 9th World Congress on Railway Research (WCRR-2011). World Congress on Railway Research, Lille, France

51. Hiensch E, et al (2006) Relationship between track geometry disturbances and the development of rolling contact fatigue damage. In: Proc. 7th World Congress on Railway Research (WCRR 2006), Montreal
52. Jaschinski A et al (1999) The application of roller rigs to railway vehicle dynamics. Veh Syst Dyn 31(5-6):345-392

53. Armstrong T, Thompson D (2006) Use of a reduced scale model for the study of wheel/rail interaction. Proc Inst Mech Eng, Part F: J Rail Rapid Transit 220(3):235-246

54. Eom BG, Kang BB, Lee HS (2011) Design of small-scaled derailment simulator for investigating bogie dynamics. Int J Railw 4(2): $50-55$

55. Koch J et al (2006) Curve squeal of urban rolling stock - part 2: parametric study on a 1/4 scale test rig. J Sound Vib 293(3):701709

56. Spoorenberg RC, Snijder HH, Hoenderkamp JCD (2011) Finite element simulations of residual stresses in roller bent wide flange sections. J Constr Steel Res 67(1):39-50

57. Gandhi AH, Raval HK (2008) Analytical and empirical modeling of top roller position for three-roller cylindrical bending of plates and its experimental verification. J Mater Process Technol 197(13):268-278

58. Li Z et al (2008) An investigation into the causes of squats - correlation analysis and numerical modeling. Wear 265(9):1349-1355

59. Oregui M, et al. (2016) Monitoring bolt tightness of rail joints using axle box acceleration measurements. Struct Control Health Monit 24(2): 1848

60. Grassie SL (2009) Rail corrugation: characteristics, causes, and treatments. Proc Inst Mech Eng, Part F: J Rail Rapid Transit 223(6):581-596

61. Grassie S, Kalousek J (1993) Rail corrugation: characteristics, causes and treatments. Proc Inst Mech Eng, Part F: J Rail Rapid Transit 207(1):57-68

62. Magel, E., et al. (2004) Control of rolling contact fatigue of rails, In AREMA 2004 annual conference. Nashville

63. Oregui Echeverria-Berreyarza M (2015) Vertical railway track dynamics: from measurements to numerical modelling. Ph.D thesis. Delft University of Technology, Delft 